\title{
Uso de aditivos em rações para suínos nas fases de creche, crescimento e terminação ${ }^{1}$
}

\section{Otto Mack Junqueira ${ }^{2}$, Luis Carlos Garibaldi Simon Barbosa ${ }^{3}$, Adriana Aparecida Pereira ${ }^{2}$, Lúcio Francelino Araújo ${ }^{4}$, Manoel Garcia Neto ${ }^{3}$, Marcos Franke Pinto ${ }^{3}$}

\footnotetext{
1 Pesquisa finaciada pela empresa Sumitomo.

2 Faculdade de Ciências Agrárias e Veterinárias - UNESP - Câmpus de Jaboticabal.

${ }^{3}$ Faculdade de Odontologia e Curso de Medicina Veterinária - UNESP - Campus de Araçatuba.

${ }^{4}$ Faculdade de Zootecnia e Engenharia de Alimentos - USP - Campus de Pirassununga.
}

RESUMO - Este trabalho foi conduzido com o objetivo de verificar o efeito da adição de antibiótico, probiótico, prebiótico e gluconato de sódio para suínos no período de 28 a 142 dias de idade, correspondente às fases de creche, crescimento e terminação. Foram utilizados 168 leitões desmamados aos 21 dias de idade, distribuídos em delineamento inteiramente casualizado em 42 baias com quatro suínos machos castrados em cada unidade experimental, com seis repetições e sete dietas: ração basal (controle negativo); ração basal + antibiótico; ração basal + probiótico; ração basal + prebiótico; ração basal + probiótico + prebiótico (simbiótico); ração basal + gluconato de sódio; ração basal + gluconato de sódio + probiótico. O desempenho dos animais diferiu entre as dietas e foi melhor nos animais que receberam ração com aditivos no período de 28 a 142 dias de idade. Entre os aditivos, o simbiótico foi mais eficiente, pois promoveu os melhores resultados de ganho de peso e conversão alimentar. Do mesmo modo, a adição de gluconato de sódio + probiótico, prebiótico e probiótico nas rações foi mais eficiente que a adição de antibiótico. A utilização dos aditivos avaliados em substituição ao antibiótico não compromete as características de carcaça e a morfometria intestinal. A associação do probiótico e prebiótico (simbiótico) estudados melhora o desempenho dos suínos nas fases de creche, crescimento e terminação.

Palavras-chave: antibiótico, gluconato de sódio, prebiótico, probiótico, simbiótico

\section{Use of additives in feed for swine in nursery, growing and finishing phases}

\begin{abstract}
The objective of this study was to evaluate the effect of adding antibiotics, probiotics, prebiotics, symbiotic and sodium gluconate for swine from 28 to 142 days of age, corresponding to the nursery, growing and finishing phases. One hundred and sixty-eight piglets were used weaned at 21 days in a randomized complete design in 42 pens with four male piglets in each experimental unit with six replications and seven treatments: control basal feed; basal feed + antibiotic; basal feed + probiotic; basal feed + prebiotic; basal feed + probiotic + prebiotic (symbiotic); basal feed + sodium gluconate; basal feed + sodium gluconate + probiotic. The animals performance differed among he treatmentsand was best in the animals that received feed with additive from 28 to 142 days of age. Among the feeds with additive, symbiotic was more efficient, presenting the best results in weight gain and feed conversion. Similarly, the addition of sodium + probiotic, prebiotic and probiotic in the feeds was more efficient than antibiotic addition. The use of the evaluated additives substituting the antibiotics did not harm the or the intestinal morphometry. The combination of probiotic and prebiotic (symbiotic) improves the swine performance in the nursery, growing and finishing phases.
\end{abstract}

Key Words: antibiotic, prebiotic, probiotic, sodium gluconate, symbiotic

\section{Introdução}

A empresa suinícola, para concorrer de forma participativa no mercado internacional, deve adaptar-se à tendência de não-utilização de antibióticos, mesmo conhecendo seus benefícios no desempenho animal.
Entre as vantagens da utilização de aditivos como promotores de crescimento, destacam-se a ausência do fenômeno de resistência bacteriana e a manutenção da produtividade dos animais.

Vários microrganismos são usados como probióticos, entre eles, as bactérias não-ácido-lácticas, como os 
Bacillus, cuja principal vantagem é sua capacidade de esporular, que lhes confere maior sobrevivência durante o trânsito estomacal e durante a elaboração, o transporte e o armazenamento das rações. Como os Bacillus spp são microrganismos não-colonizadores, seu principal modo de ação é a competição com outras bactérias por nutrientes.

O prebiótico à base de polpa de coco processada por enzimas possui alto teor de manose, que não são digeridos pelas enzimas digestivas normais. Desse modo, ocorre a fixação da manose às bactérias patogênicas, inibindo sua aderência na parede intestinal. Esse prebiótico também contém outros oligossacarídeos que são digeridos pelas bactérias lácteas, favorecendo o crescimento dos microrganismos probióticos no intestino e inibindo o crescimento de bactérias patogênicas.

O gluconato de sódio deriva da oxidação incompleta da glicose por colônias de Gliconobacter. Aproximadamente $70 \%$ do gluconato ingerido escapa para o intestino grosso e é fermentado por bactérias benéficas, como os Lactobacillus e Bifidobacteruium, cujo produto final da fermentação é o lactato e o acetato, que serão convertidos em butirato por bactérias que utilizam ácidos, como a Megasphaera elsdenii.

A interação entre probiótico e prebiótico (simbiótico) pode favorecer a adaptação do probiótico ao substrato do prebiótico, potencializando o efeito de ambos. Esses aditivos possuem ação trófica no trato gastrintestinal, favorecendo o processo mitótico na região cripta-vilo, aumentando o número de células e o tamanho dos vilos, uma vez que, ao inibir a proliferação excessiva de bactérias patogênicas no trato intestinal, reduzirão a produção de metabólitos tóxicos que afetam o epitélio intestinal, prejudicando a absorção de nutrientes.

Este trabalho foi conduzido com o objetivo de avaliar a adição de aditivos nas rações de suínos sobre o desempenho, as características de carcaça e a morfometria intestinal.

\section{Material e Métodos}

O experimento foi conduzido no Laboratório de Suinocultura da Faculdade de Engenharia de Alimentos e Zootecnia - USP, Campus de Pirassununga, São Paulo, utilizando-se 168 leitões (Landrace $\times$ Large White) desmamados aos 21 dias de idade, com peso médio inicial de $6,9 \mathrm{~kg}$. Os animais foram distribuídos em delineamento inteiramente casualizados em 42 baias, com quatro suínos machos castrados em cada unidade experimental, com sete dietas, cada uma com seis repetições. Os animais foram submetidos a um período de adaptação de sete dias, portanto, o experimento foi iniciado aos 28 dias de idade.
$\mathrm{Na}$ creche, os animais foram alojados em baias suspensas $\left(2,00 \times 1,20 \mathrm{~m}^{2}\right)$ dotadas de comedouros automáticos e bebedouros do tipo chupeta em uma sala de alvenaria. A área abaixo do bebedouro era constituída de piso metálico vazado, enquanto o restante era de concreto compacto correspondendo à área adjacente aos comedouros. Durante as primeiras semanas, o aquecimento foi realizado por meio de resistências em placas localizadas sob o chão das baias. Conforme os animais foram adquirindo controle sobre o seu sistema termorregulatório, a temperatura, assim como a ventilação no interior da creche, foi controlada por sistema de cortina, com a finalidade de manter o conforto térmico dos animais.

Aos 71 dias de idade, os animais foram transferidos para as baias de crescimento/terminação mantendo os mesmos grupos de animais formados na creche. Essas baias possuíam $6 \mathrm{~m}^{2}$, constituídos de uma área de concreto adjacente ao comedouro e, ao fundo, uma lâmina de água corrente de aproximadamente $10 \mathrm{~cm}$ de profundidade e $80 \mathrm{~cm}$ de largura onde se localizava o bebedouro.

A temperatura e a umidade foram aferidas diariamente por meio de termômetros de máxima e mínima, distribuídos em diferentes locais no interior da sala de creche e do galpão de crescimento/terminação.

A ração e a água foram fornecidas à vontade durante todo o período experimental. As rações experimentais foram: ração basal sem aditivo (controle negativo), ração basal +10 ppm do antibiótico (Surmax ${ }^{\circledR}$, à base de avilamicina), ração basal + probiótico (Toyocerin ${ }^{\circledR}$, à base de Bacillus toyoi na concentração de $5 \times 10^{9}$ esporos por grama do produto), ração basal + prebiótico (Coccoace ${ }^{\circledR}$, à base de oligossacarídeos), ração basal + probiótico + prebiótico (simbiótico), ração basal + de gluconato de sódio (Sumiflora ${ }^{\circledR}$ contém $98 \%$ de gluconato de sódio), ração basal + gluconato de sódio + probiótico.

Os aditivos alternativos ao antibiótico foram adicionados à ração de acordo com o período de crescimento dos animais. Assim, no período inicial 1 e 2 (28 a 71 dias de idade), foram adicionados: $1,50 \mathrm{~kg} / \mathrm{t}$ de ração do probiótico; $0,50 \mathrm{~kg} / \mathrm{t}$ do prebiótico e $0,25 \mathrm{~kg} / \mathrm{t}$ do gluconato de sódio; no período de crescimento ( 72 a 104 dias de idade) foram adicionados: $1,00 \mathrm{~kg} / \mathrm{t}$ de ração do probiótico; $0,20 \mathrm{~kg} / \mathrm{t}$ do prebiótico e $0,20 \mathrm{~kg} / \mathrm{t}$ do gluconato de sódio; no período de terminação (105 dias aos 142 dias de idade) foram adicionados: $0,20 \mathrm{~kg} / \mathrm{t}$ de ração do probiótico; $0,20 \mathrm{~kg} / \mathrm{t}$ do prebiótico e $0,20 \mathrm{~kg} / \mathrm{t}$ do gluconato de sódio. Os níveis do simbiótico e do gluconato de sódio + probiótico foram as somas dos dois aditivos para cada período. 
Tabela 1 - Composição em ingredientes e nutricional (calculadas) das rações basais

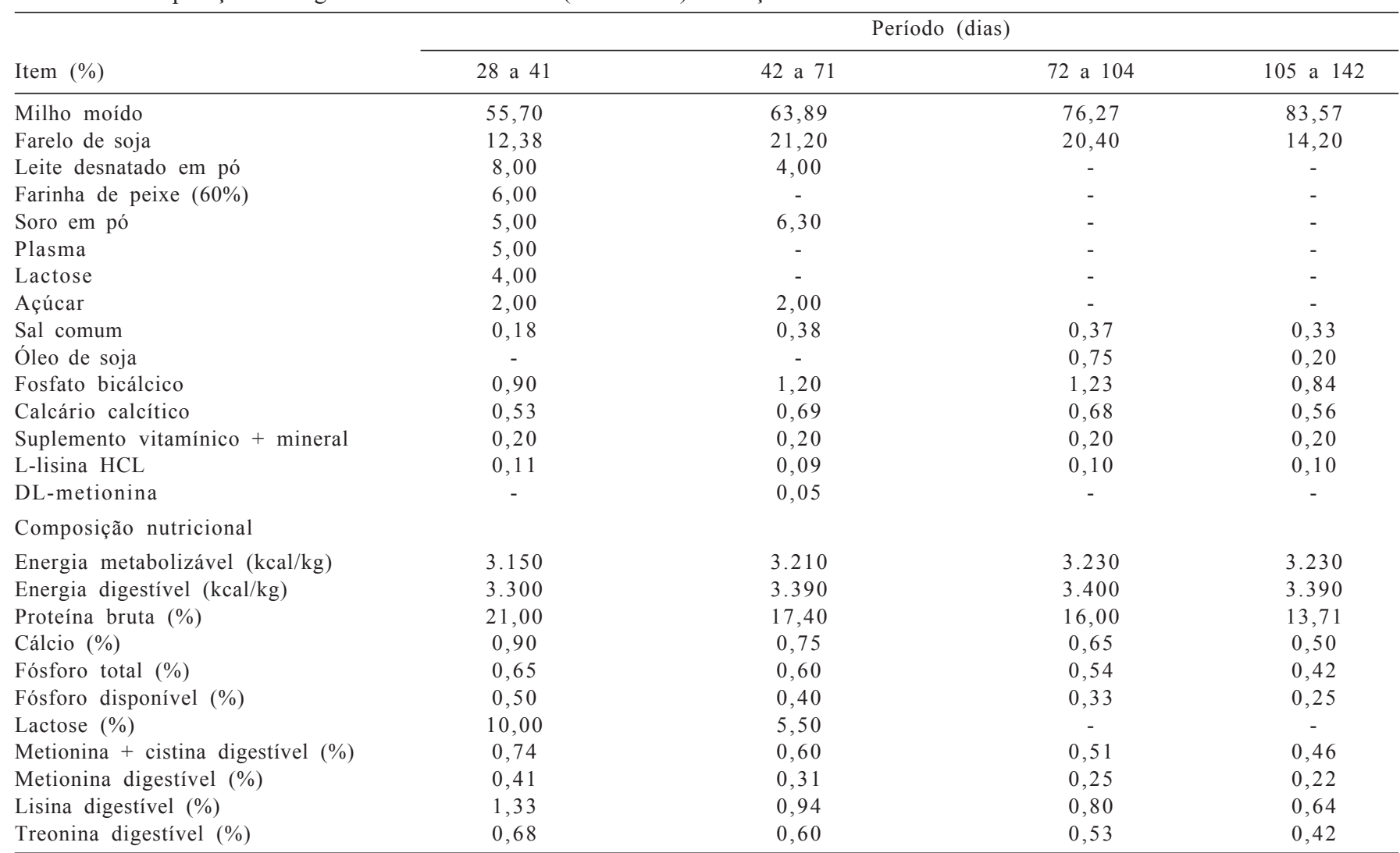

Os níveis de proteína, aminoácidos, minerais e vitaminas foram preconizados de acordo com Rostagno et al. (2005) para cada uma das fases em estudo (Tabela 1).

Como parâmetros de desempenho foram avaliados o ganho de peso, o consumo de ração e a conversão alimentar aos $41 ; 71 ; 104$ e 142 dias de idade.

Ao final do experimento, com os animais apresentando 142 dias de idade, foi abatido um animal de cada unidade experimental. Após todos os procedimentos de abate, evisceração e divisão das carcaças, as meias-carcaças foram pesadas para obtenção do peso de carcaça quente. Em seguida, foram submetidas a uma análise para tipificação eletrônica de rendimento de carcaças utilizando a pistola automática Hennessy GP4/BP4, que foi introduzida de 6 a $8 \mathrm{~cm}$ da linha média, acima da última costela das meias-carcaças esquerdas dos suínos.

As características de carcaça avaliadas foram peso da carcaça, rendimento de carcaça, rendimento de lombo, rendimento de pernil, espessura de toucinho, espessura de músculo e porcentagem de carne magra.

Os cortes histológicos intestinais (duodeno e jejuno) foram avaliados quanto à altura das vilosidades e à profundidade de cripta, utilizando-se amostras de aproximadamente $2,5 \mathrm{~cm}$ de comprimento retiradas da porção média dos segmentos do duodeno e jejuno coletados de cada animal. As amostras foram abertas pela borda mesentérica, lavadas em água destilada, estendidas pela túnica serosa e fixadas em solução de Bouin. Depois de 24 horas nesta solução, foram lavadas em álcool etílico $70 \% \mathrm{e}$ posteriormente desidratadas em série crescente de alcoóis. Após desidratação, foram recortadas, diafanizadas em benzol e incluídas em parafinas para se obterem cortes longitudinais da mucosa intestinal.

Em cada lâmina histológica, foram realizados cinco cortes semisseriados com $5 \mathrm{~mm}$ de espessura, de modo que, entre um corte e o subsequente, foram desprezados cinco cortes. Os cortes foram corados segundo a técnica hematoxilina de Harris-eosina. A análise morfométrica do intestino delgado foi realizada pelo fotomicroscópio Leica DM 2000 com aumento de 10x.

Os dados foram submetidos à análise de variância pelo procedimento General Linear Model (GLM) do SAS (2001) efetuando-se comparações múltiplas de médias, pelo teste Tukey (5\%).

\section{Resultados e Discussão}

No período de 28 a 41 dias de idade, não houve diferença no ganho de peso dos animais entre as rações experimentais (Tabela 2). No período de 42 a 71 dias de 
Tabela 2 - Desempenho de suínos alimentados com rações com diferentes aditivos e em vários períodos experimentais

\begin{tabular}{|c|c|c|c|c|c|}
\hline \multirow[t]{2}{*}{ Item } & \multicolumn{5}{|c|}{ Fase (dias) } \\
\hline & 28 a 41 & 42 a 71 & 72 a 104 & 105 a 142 & 28 a 142 \\
\hline & \multicolumn{5}{|c|}{ Ganho de peso (kg) } \\
\hline Controle negativo & $5,91 \mathrm{a}$ & $18,73 b$ & $28,50 \mathrm{~b}$ & $34,70 \mathrm{~b}$ & $94,73 b$ \\
\hline Antibiótico & $6,08 \mathrm{a}$ & $18,41 b$ & $28,98 b$ & $35,12 \mathrm{ab}$ & $95,42 \mathrm{ab}$ \\
\hline Probiótico & $6,10 \mathrm{a}$ & $19,04 \mathrm{a}$ & $29,13 \mathrm{ab}$ & $35,00 \mathrm{ab}$ & $96,17 \mathrm{ab}$ \\
\hline Prebiótico & $6,00 \mathrm{a}$ & $19,84 \mathrm{a}$ & $30,45 \mathrm{a}$ & $35,07 \mathrm{ab}$ & $98,36 \mathrm{a}$ \\
\hline Simbiótico & $6,10 \mathrm{a}$ & $19,98 \mathrm{a}$ & $30,83 \mathrm{a}$ & $36,08 \mathrm{a}$ & $99,87 \mathrm{a}$ \\
\hline Gluconato de sódio & $5,93 a$ & $18,50 \mathrm{~b}$ & $29,60 \mathrm{ab}$ & $34,93 b$ & $95,89 \mathrm{ab}$ \\
\hline Gluconato+probiótico & $6,00 \mathrm{a}$ & $19,33 \mathrm{a}$ & $30,13 \mathrm{a}$ & $35,93 \mathrm{a}$ & $98,27 \mathrm{a}$ \\
\hline \multirow[t]{2}{*}{ Coeficiente de variação (\%) } & 3,18 & 3,03 & 3,63 & 3,81 & 4,02 \\
\hline & \multicolumn{5}{|c|}{ Consumo de ração $(\mathrm{kg})$} \\
\hline Controle negativo & $8,51 \mathrm{a}$ & $34,28 \mathrm{a}$ & $72,96 \mathrm{~b}$ & $103,41 \mathrm{a}$ & $219,16 b$ \\
\hline Antibiótico & $8,76 \mathrm{a}$ & $32,95 \mathrm{a}$ & $66,65 \mathrm{ab}$ & $101,85 \mathrm{a}$ & $210,21 \mathrm{ab}$ \\
\hline Probiótico & $8,48 \mathrm{a}$ & $33,51 \mathrm{a}$ & $64,09 \mathrm{a}$ & $100,80 \mathrm{a}$ & $206,88 \mathrm{a}$ \\
\hline Prebiótico & $8,40 \mathrm{a}$ & $35,31 \mathrm{a}$ & $67,90 \mathrm{ab}$ & $101,00 \mathrm{a}$ & $212,61 \mathrm{ab}$ \\
\hline Simbiótico & $8,60 \mathrm{a}$ & $34,56 a$ & $68,13 \mathrm{ab}$ & $100,66 \mathrm{a}$ & $211,95 \mathrm{ab}$ \\
\hline Gluconato de sódio & $8,60 \mathrm{a}$ & $33,67 \mathrm{a}$ & $71,63 \mathrm{~b}$ & $101,30 \mathrm{a}$ & $215,20 \mathrm{ab}$ \\
\hline Gluconato+probiótico & $8,64 \mathrm{a}$ & $33,25 \mathrm{a}$ & $69,30 \mathrm{ab}$ & $100,96 \mathrm{a}$ & $212,15 \mathrm{ab}$ \\
\hline \multirow[t]{2}{*}{ Coeficiente de variação (\%) } & 2,36 & 3,81 & 4,13 & 4,01 & 4,83 \\
\hline & \multicolumn{5}{|c|}{ Conversão alimentar (kg/kg) } \\
\hline Controle negativo & $1,44 \mathrm{a}$ & $1,83 \mathrm{~b}$ & $2,56 b$ & $2,98 b$ & $2,31 b$ \\
\hline Antibiótico & $1,44 \mathrm{a}$ & $1,79 \mathrm{ab}$ & $2,30 \mathrm{a}$ & $2,90 \mathrm{ab}$ & $2,20 \mathrm{ab}$ \\
\hline Probiótico & $1,39 a$ & $1,76 \mathrm{ab}$ & $2,20 \mathrm{a}$ & $2,88 \mathrm{ab}$ & $2,15 \mathrm{ab}$ \\
\hline Prebiótico & $1,40 \mathrm{a}$ & $1,78 \mathrm{ab}$ & $2,23 \mathrm{a}$ & $2,88 \mathrm{ab}$ & $2,16 \mathrm{ab}$ \\
\hline Simbiótico & $1,41 \mathrm{a}$ & $1,73 \mathrm{a}$ & $2,21 \mathrm{a}$ & $2,79 a$ & $2,12 \mathrm{a}$ \\
\hline Gluconato de sódio & $1,45 \mathrm{a}$ & $1,82 \mathrm{~b}$ & $2,42 \mathrm{ab}$ & $2,90 \mathrm{ab}$ & $2,24 \mathrm{ab}$ \\
\hline Gluconato+probiótico & $1,44 \mathrm{a}$ & $1,72 \mathrm{a}$ & $2,30 \mathrm{a}$ & $2,81 \mathrm{a}$ & $2,16 \mathrm{ab}$ \\
\hline Coeficiente de variação (\%) & 3,18 & 2,73 & 4,00 & 4,13 & 3,89 \\
\hline
\end{tabular}

Médias seguidas de mesma letra, na mesma coluna, não diferem $(\mathrm{P}<0,05)$ pelo teste Tukey.

idade, os animais que receberam rações com probiótico, prebiótico, simbiótico e gluconato de sódio + probiótico apresentaram maior ganho de peso e a ração com simbiótico promoveu ganho de peso $6,67 \%$ maior em relação àquela sem aditivo (Tabela 2 ).

No período de 72 a 104 dias de idade, não houve diferença no ganho de peso entre os animais que consumiram a ração controle e aquela com antibiótico (Tabela 2), porém os animais alimentados com a ração contendo antibiótico diferiram daqueles mantidos com as rações com prebiótico, simbiótico ou gluconato de sódio + probiótico. Esses aditivos proporcionaram melhora de 6,$84 ; 8,18$ e $5,72 \%$, respectivamente, no ganho de peso dos animais. A ração controle e aquelas contendo simbiótico e gluconato de sódio + probiótico proporcionaram melhora de 3,98 e 3,54\% no ganho de peso dos 105 aos 142 dias de idade.

De modo geral, os animais que receberam prebiótico, simbiótico e gluconato de sódio + probiótico na ração apresentaram maior ganho de peso em comparação àqueles que receberam ração controle, em decorrência da ação dos aditivos, que proporcionam a manutenção do equilíbrio da flora intestinal. Além disso, esses aditivos agem no desenvolvimento gastrintestinal, contribuindo para digestão e absorção dos nutrientes da dieta, assim como na ativação do sistema imune, protegendo o animal dos desafios microbiológicos.

Esses resultados diferem dos obtidos por Fedalto et al. (2002), que avaliaram o efeito do probiótico (Bacillus toyoi) em comparação a um antibiótico adicionado no premix comercial e não observaram melhora no ganho de peso de leitões até os 63 dias de idade. Sanches et al. (2006) também não encontraram diferença significativa entre a utilização de antibióticos, probióticos, prebióticos e simbióticos em rações para leitões dos 23 aos 58 dias de idade.

Como a eficácia dos produtos depende estritamente dos níveis utilizados e das características de cada aditivo, é muito difícil estabelecer paralelos entre estudos e comparar resultados.

No período entre 28 a 41, 42 a 71 e 105 a 142 dias de idade, não houve diferença no consumo de ração entre os aditivos. Já no período de 72 a 104 dias de idade, o probiótico promoveu diminuição de $12,16 \%$ no consumo de ração dos animais em comparação à dieta controle negativo. Desta forma, em todo o período experimental, de 28 a 142 dias de idade, o consumo de ração dos animais alimentados com rações contendo probiótico diminuiu $5,60 \%$ em relação ao dos animais alimentados com a ração 
controle, mas não houve diferença entre os outros aditivos (Tabela 2).

A redução no consumo de ração dos suínos alimentados com a ração contendo probiótico pode estar relacionada ao fato de os animais terem se tornado mais eficientes em digerir os alimentos e utilizar os nutrientes da dieta, uma que o ganho de peso foi similar ao obtido com os outros aditivos. Santos et al. (2002) também evidenciaram diminuição do consumo de ração quando utilizaram probiótico na ração de leitões nas fases de aleitamento e de creche.

Em contrapartida, Utiyama et al. (2006) avaliaram o efeito de antimicrobianos (bacitracina de zinco), prebióticos, probióticos (Bacillus subtilis e Bacillus licheniformis) e extratos vegetais para leitões de 15 a 35 dias de idade e observaram que as rações com antimicrobiano e com prebiótico promoveram maior consumo de ração. A divergência de resultados pode ser atribuída, entre outros fatores, à composição dos aditivos utilizados e ao desafio imunológico a que os animais foram submetidos.

No período de 28 a 41 dias de idade, os resultados de conversão alimentar não diferiram entre os aditivos (Tabela 2), portanto pode ter ocorrido baixo desafio imunológico na fase de creche e esse desafio pode ter aumentado ao longo do tempo, já que nas fases seguintes houve resposta da conversão alimentar aos aditivos da ração.

No período entre 42 a 71 dias de idade, as rações com simbiótico e gluconato de sódio + probiótico, proporcionaram aos leitões melhora na conversão alimentar de, respectivamente, 5,46 e 6,01\% em comparação à conversão alimentar dos leitões que consumiram ração controle (Tabela 2).

No período de 72 a 104 dias de idade, houve diferença na conversão alimentar dos animais alimentados com ração controle negativo e os animais alimentados com rações contendo antibiótico, probiótico, prebiótico, simbiótico e gluconato de sódio + probiótico, nos quais esses aditivos permitiram melhora de, respectivamente, 10,$16 ; 14,06 ; 12,89$; 13,$67 ;$ e $10,16 \%$ (Tabela 2).

No período entre 105 a 142 dias de idade, verificou-se efeito significativo entre o controle negativo e a adição de simbiótico e gluconato de sódio + probiótico nas rações dos suínos, com melhora de $6,38 \%$ e $5,70 \%$ na conversão alimentar dos animais que receberam rações com esses aditivos (Tabela 2). Apesar do efeito menos pronunciado observado na fase anterior (72 a 104 dias), recomenda-se o uso de simbiótico e gluconato de sódio + probiótico na fase de terminação.

Ao analisar todo o período experimental, compreendido entre 28 a 142 dias de idade, o simbiótico proporcionou melhor resultado de conversão alimentar, ou seja, os animais que receberam simbiótico na ração foram $8,23 \%$ mais eficientes na transformação do alimento em ganho de peso em comparação àqueles que não receberam aditivo na ração. Os melhores índices de conversão alimentar podem ser resultado da melhor absorção dos nutrientes aliada ao menor gasto de energia para manutenção do trato gastrintestinal. Por outro lado, Cuevas et al. (2000) não verificaram melhora na adição de Bacillus toyoi sobre esse parâmetro em estudo.

Não houve diferença sobre as características de carcaça avaliadas (peso da carcaça, rendimento de carcaça, rendimento de pernil, rendimento de lombo, espessura de toucinho, espessura do músculo e percentagem de carne magra) nos suínos abatidos aos 142 dias de idade (Tabela 3 ). Esperava-se que a inclusão dos aditivos na ração auxiliasse no equilíbrio do trato gastrintestinal, possibilitando melhor utilização da proteína para deposição muscular pelos animais.

De forma consistente com esses resultados, Chiquieri et al. (2006) também não observaram diferenças entre o uso de antibióticos, probióticos e/ou prebióticos sobre as características de carcaça de suínos. Do mesmo modo, Rekiel et al. (2005) não notaram efeitos nos parâmetros de carcaça de suínos quando estudaram a adição de mananoligossacarídeos e antibióticos na dieta.

Tabela 3 - Características de carcaça de suínos aos 142 dias de idade alimentados com rações com diferentes aditivos

\begin{tabular}{|c|c|c|c|c|c|c|c|c|}
\hline \multirow[t]{2}{*}{ Característica } & \multirow{2}{*}{$\begin{array}{l}\text { Controle } \\
\text { negativo }\end{array}$} & \multicolumn{6}{|c|}{ Aditivo } & \multirow[b]{2}{*}{$\mathrm{CV}(\%)$} \\
\hline & & Antibiótico & Probiótico & Prebiótico & Simbiótico & $\begin{array}{l}\text { Gluconato } \\
\text { de sódio }\end{array}$ & $\begin{array}{c}\text { Gluconato }+ \\
\text { probiótico }\end{array}$ & \\
\hline Rendimento de carcaça (\%) & 76,63 & 75,89 & 76,04 & 77,23 & 76,01 & 76,85 & 75,83 & 9,85 \\
\hline Rendimento de pernil (\%) & 26,81 & 27,03 & 27,80 & 27,77 & 27,31 & 26,92 & 26,59 & 11,14 \\
\hline Rendimento de lombo (\%) & 8,03 & 8,54 & 7,98 & 8,39 & 8,61 & 8,14 & 7,99 & 13,23 \\
\hline Espessura de toucinho (mm) & 17,00 & 17,22 & 17,89 & 19,05 & 18,14 & 17,16 & 18,73 & 15,98 \\
\hline
\end{tabular}


Tabela 4 - Morfometria intestinal dos suínos aos 142 dias de idade

\begin{tabular}{|c|c|c|c|c|}
\hline \multirow[b]{2}{*}{ Item } & \multicolumn{2}{|c|}{ Duodeno } & \multicolumn{2}{|c|}{ Jejuno } \\
\hline & Profundidade de cripta $(\mu \mathrm{m})$ & Altura de vilosidade $(\mu \mathrm{m})$ & Profundidade de cripta $(\mu \mathrm{m})$ & Altura de vilosidade $(\mu \mathrm{m})$ \\
\hline Controle negativo & 324,2 & 280,3 & 129,7 & 252,9 \\
\hline Antibiótico & 382,2 & 285,1 & 159,6 & 269,8 \\
\hline Probiótico & 364,2 & 302,0 & 116,4 & 267,9 \\
\hline Prebiótico & 378,2 & 272,6 & 142,6 & 289,3 \\
\hline Simbiótico & 338,2 & 292,4 & 198,2 & 278,4 \\
\hline Gluconato de sódio & 371,5 & 297,8 & 187,6 & 295,6 \\
\hline Gluconato + probiótico & 322,8 & 312,7 & 147,9 & 246,3 \\
\hline CV $(\%)$ & 29,65 & 31,89 & 25,63 & 32,85 \\
\hline
\end{tabular}

Em contrapardida, estudos com probióticos apontam algumas diferenças nas características de carcaças dos suínos. Quadros et al. (2001) observaram aumento de 11\% na profundidade do músculo Longissimus dorsi em relação à obtida com uma dieta controle.

Não houve diferença nos parâmetros de morfometria intestinal avaliados (Tabela 4). Chiquieri et al. (2006) também não verificaram efeito do uso de probiótico (Saccharomyces cerevisiae) e/ou prebiótico (MOS) sobre a altura de vilosidades do duodeno de suínos aos 120 dias de idade. Esses resultados não satisfazem as expectativas de que o consumo de probiótico e/ou prebiótico na ração melhora a qualidade da mucosa intestinal, como demonstrado por Jonsson \& Henningsson (1991), que encontraram diferenças na morfologia intestinal de leitões alimentados com rações contendo ou não probiótico, confirmando que a utilização de promotores de crescimento tem melhor efeito nas fases de aleitamento e creche.

Outros autores também avaliaram o efeito de extratos vegetais e antimicrobianos sobre a morfometria intestinal de leitões aos 56 dias de idade e não observaram efeito dos aditivos sobre a profundidade de cripta e altura de vilosidades do duodeno e do jejuno (Oetting et al., 2006). Da mesma forma, Biagi et al. (2006) não notaram efeito dos níveis $(0,3,6$ e $12 \mathrm{ppm})$ de gluconato de sódio sobre a profundidade de cripta e altura de vilosidade do jejuno, íleo e ceco de suínos aos 70 dias de idade.

O fato de os animais terem sido abatidos com mais idade e alguns aditivos utilizados, como o prebiótico e gluconato de sódio, estimularem o crescimento de microrganismos que atuam na região posterior do intestino podem explicar a ausência do efeito dos aditivos sobre a morfometria intestinal do duodendo e jejuno. Além disso, o alto coeficiente de variação desse parâmetro em diversas pesquisas realizadas com suínos dificulta a correta comparação entre resultados.

\section{Conclusões}

Entre os aditivos avaliados, o simbiótico (probiótico + prebiótico) proporciona os melhores resultados de desempenho dos suínos no período de 28 a 142 dias de idade e constitui uma alternativa viável ao uso de antibióticos na ração de suínos em todas as fases de produção. A utilização dos aditivos como promotores de crescimento não compromete as características de carcaça e a morfometria intestinal dos animais.

\section{Literatura Citada}

BIAGI, G.; PIVA, A.; MOSCHINI, M. et al. Effect of gluconic acid on piglet growth performance, intestinal microflora, and intestinal wall morphology. Journal of Animal Science, v.84, p.370-378, 2006.

CHIQUIERI, J.M.S.; SOUSA, J.C.D.; VENTURA, B.G. Probiotico y prebiotico em la alimentation de cerdos em crescimento y terminacyon. Archivo Zootecnico, v.55, p.305-308, 2006.

CUEVAS, A.C.; GONZALES, E.A.; HUGUENIN, T.C. et al. El efecto del Bacillus toyoi sobre el comportamento productivo em pollos de engorda. Veterinária México, v.31, n.4, p.301-308, 2000.

FEDALTO, L.M.; TKACZ, M.; ADER, L.P. Probioticos na alimentação de leitões do desmame ao 63 dias de idade. Archives of Veterinary Science, v.7, p.83-88, 2002.

JONSSON, E.; HENNINGSSON, S. Establisment in the piglet gut of lactobacilli capable of degrading mixed-linked "B"-D-glucans. Journal Applied Bacteriology, v.70, p.512-516, 1991.

OetTing, L.L.; UTIYAMA, C.E.; GIANI, P.A. et al. Efeitos de extratos vegetais e antimicrobianos sobre a digestibilidade aparente, o desempenho, a morfometria dos órgãos e a histologia intestinal de leitões recém- desmamados. Revista Brasileira de Zootecnia, v.35, n.4, p.1389-1397, 2006.

QUADROS, A.R.B.; KIEFER, C.; RIBEIRO, N.L.C. et al. Características qualitativas da carne de suínos alimentados com rações contendo ou não probióticos. In: REUNIÃO ANUAL DA SOCIEDADE BRASILEIRA DE ZOOTECNIA, 2001, Piracicaba. Anais... Piracicaba: Sociedade Brasileira de Zootecnia, 2001. p.794-795.

REKIEL, A.; WIECEK, J.; DZIUBA, M. Effect of feed additives on the results of fattening and selected slaughter and quality traits of pork meat of pigs with different genotypes. Journal of Animal Science, v.50, n.12, p.561-567, 2005.

Rostagno, H,S; ALBInO, L.F.T; DOnZELE, J.L. Tabelas brasileiras para suínos e aves: Composição de alimentos e exigências nutricionais, Viçosa, MG: Universidade Federal de Viçosa, 2005. 186p. 
SANCHES, A.L.; LIMA, J.A.; FIALHO, E.T. et al. Utilização de probiótico, prebiótico e simbiótico em rações de leitões ao desmame. Ciências Agrotécnica, v.30, n.4, p.774-777, 2006.

SANTOS, M.S.; FERREIRA, C.L.L.; GOMES, P.C. et al. Administração de Lactobacillus sp. em leitões na fase de aleitamento e na fase de creche. Ciências Agrotécnica, v.26, n.1, p.165-173, 2002.
STATISTICAL ANALYSIS SYSTEM - SAS. SAS/STAT: user's guide. Version 8.2. Cary: Statistical Analysis System Institute, 2001. 943p. UTIYAMA, C.A.; OETTING, L.L.; GIANI, P.A. et al. Efeitos de antimicrobianos, prebióticos, probióticos e extratos vegetais sobre a microbiota intestinal, a freqüência de diarréia e o desempenho de leitões recém desmamados. Revista Brasileira de Zootecnia, v.35, n.6, p.2359-2367, 2006. 